\title{
Property of Lysosomal Storage Disease Associated with Midbrain Pathology in the Central Nervous System of Lamp-2-Deficient Mice
}

\author{
Akiko Furuta, ${ }^{*}$ Hisae Kikuchi, ${ }^{\dagger}$ Hiromi Fujita ${ }^{\dagger}$ Daisuke Yamada ${ }^{\dagger}$ Yuuki Fujiwara, ${ }^{\dagger \dagger}$ Tomohiro Kabuta, $^{\dagger}$ Ichizo Nishino, ${ }^{\S}$ \\ Keiji Wada, ${ }^{\dagger}$ and Yasuo Uchiyama*

\begin{abstract}
From the Department of Cellular and Molecular Neuropathology, * Juntendo University Graduate School of Medicine, Tokyo; the Departments of Degenerative Neurological Diseases ${ }^{\dagger}$ and Neuromuscular Research, ${ }^{\S}$ National Institute of Neuroscience, National Center of Neurology and Psychiatry, Kodaira, Tokyo; and the Department of Electrical Engineering and Bioscience, ${ }^{\ddagger}$ Graduate School of Advanced Science and Engineering, Waseda University, Shinjuku, Tokyo, Japan
\end{abstract}

\author{
Accepted for publication \\ February 12, 2015. \\ Address correspondence to Akiko \\ Furuta, M.D., Ph.D., Department \\ of Cellular and Molecular \\ Neuropathology, Juntendo Uni- \\ versity Graduate School of Med- \\ icine, Hongo 2-1-1, Bunkyo-ku, \\ Tokyo 113-8421, Japan. \\ E-mail: afuruta@juntendo.ac.jp.
}

\begin{abstract}
Lysosome-associated membrane protein-2 (LAMP-2) is the gene responsible for Danon disease, which is characterized by cardiomyopathy, autophagic vacuolar myopathy, and variable mental retardation. To elucidate the function of LAMP-2 in the central nervous system, we investigated the neuropathological changes in Lamp-2-deficient mice. Immunohistochemical observations revealed that Lamp-1 and cathepsin D-positive lysosomal structures increased in the large neurons of the mouse brain. Ubiquitin-immunoreactive aggregates and concanavalin A-positive materials were detected in these neurons. By means of ultrastructural studies, we found various-shaped accumulations, including lipofuscin, glycolipid-like materials, and membranous structures, in the neurons and glial cells of Lamp-2-deficient brains. In deficient mice, glycogen granules accumulated in hepatocyte lysosomes but were not observed in neurons. These pathological features indicate lysosomal storage disease; however, the findings are unlikely a consequence of deficiency of a single lysosomal enzyme. Although previous study results have shown a large amount of autophagic vacuoles in parenchymal cells of the visceral organs, these findings were rarely detected in the brain tissue except for some axons in the substantia nigra, in which abundant activated microglial cells with increased lipid peroxidation were observed. Thus, LAMP-2 in the central nervous system has a possible role in the degradation of the various macromolecules in lysosomes and an additional function concerning protection from oxidative stress, especially in the substantia nigra. (Am J Pathol 2015, 185: 1713-1723; http://dx.doi.org/10.1016/j.ajpath.2015.02.015)
\end{abstract}

X-linked vacuolar cardiomyopathy and myopathy (Danon disease) are caused by the primary deficiency of lysosomeassociated membrane protein-2 (LAMP-2). ${ }^{1}$ Danon disease was first described as lysosomal glycogen storage disease with normal acid maltase because the cases closely resembled features of the infantile form of acid maltase deficiency (Pompe disease; glycogen storage disease type II), except that acid maltase activity was normal in the muscle. ${ }^{2}$ The muscle malfunction of Danon disease has been well investigated with biopsied specimens characterized by autophagic vacuolar myopathy with sarcolemmal features., ${ }^{3,4}$ Despite
Supported in part by Grant-in-Aid for Scientific Research (C) 23590244 from the Ministry of Education, Culture, Sports, Science and Technology (A.F.), Grant-in-Aid for Scientific Research 25290027 from the Japan Society for the Promotion of Science (K.W.), Grants-in-Aid for Scientific Research 05-32 from the Program for Promotion of Fundamental Studies in Health Sciences of the National Institute of Biomedical Innovation, Japan (K.W.), Grant-in-Aid for Creative Scientific Research 16GS0315 and Grants-in-Aid for Scientific Research on Innovative Areas 23111004 and 23110517 from the Japan Society for the Promotion of Science (Y.U.), and the Ministry of Education, Culture, Sports, Science and Technology, Japan-supported Program for the Strategic Research Foundation at Private Universities (Y.U.).

Disclosures: None declared. 
the presence of cognitive impairment in these patients, the neuropathological findings have not been investigated. Recently, we reported an autopsy case of genetically confirmed Danon disease and found distinct neuropathological changes, including features of lysosomal accumulation and senescence, ${ }^{5}$ although the role of LAMP-2 in the central nervous system (CNS) is still under investigation.

The lysosomal membrane glycoproteins, LAMP-1 and LAMP-2, are type 1 membrane proteins that consist of a short cytoplasmic tail, one transmembrane domain, and a heavily glycosylated luminal domain. ${ }^{6}$ Human LAMP-1 and LAMP-2 share $36.7 \%$ sequence identity and many structural and biochemical similarities. ${ }^{7}$ The human $L A M P 2$ gene has three splice variants: $L A M P-2 A, L A M P-2 B$, and $L A M P-2 C$. ${ }^{6}$ LAMP-2A serves as a receptor for chaperone-mediated autophagy (CMA), ${ }^{8}$ and CMA malfunction may be related to aging and lysosomal storage diseases, as well as neurodegenerative disorders such as Parkinson disease, Alzheimer disease, and polyglutamine disorders. ${ }^{9}$ Fujiwara et $\mathrm{al}^{10,11}$ discovered a novel function of LAMP-2C that mediates selective autophagy for nucleic acids. Despite the advancement of this field, results from relatively few studies confirm these functions of LAMP-2 in vivo.

Here, we examined the CNS of Lamp-2-deficient mice. All genes for Lamp2 subtypes of the mice were deleted. ${ }^{12}$ The neuropathological features were consistent with those of human Danon disease, ${ }^{5}$ suggesting that Lamp2-deficient mice are an appropriate in vivo model for human Danon disease and are, therefore, available to elucidate the mechanism and therapeutic intervention of the disease. Characteristic features, ie, accumulation of glycogen in lysosomes and enhancement of macroautophagy, are not noted in the brain. Different responses between neural cells of the CNS and parenchymal cells of visceral organs are discussed.

\section{Materials and Methods}

\section{Experimental Animals}

Littermates of male Lamp2-deficient mice and wild-type mice were used in this experiment. All of the animals were offspring from pairs of wild-type C57BL/6J male mice and hemizygote $\operatorname{Lamp} 2^{\mathrm{x} /-}$ female mice because the Lamp 2 gene is located at X chromosome Xq24. ${ }^{13}$ Lamp-2-deficient mice were provided by Dr. Paul Saftig ${ }^{12}$ and were backcrossed with C57BL/6J mice $>20$ generations in our laboratory. The mice were maintained at Juntendo University and at the National Institute of Neuroscience, National Center of Neurology and Psychiatry (Tokyo, Japan). The experiments were approved by the institute's Animal Investigation Committee.

\section{Antibodies}

The following primary antibodies were used for Western blot analysis and immunohistochemical analysis: Lamp-2
(M3/84, rat monoclonal, 1:100, Abcam, Cambridge, UK), Lamp-1 (1D4B, rat monoclonal, 1:1000, Stressgen Bioreagents, Victoria, BC, Canada), cathepsin D (rabbit polyclonal, 1:1000, Dr. Yasuo Uchiyama), light chain 3 (LC3) (rabbit polyclonal, 1:1000, Abcam), $\alpha$-synuclein (rabbit polyclonal, 1:1000 for Western blot analysis, 1:500 for immunohistochemical analysis, EMD Millipore, Billerica, MA), $\beta$-actin (mouse monoclonal, 1:10,000, Sigma-Aldrich, St. Louis, MO), ubiquitin (rabbit polyclonal, 1:200, Dako, Glostrup, Denmark), glial fibrillary acidic protein (rabbit polyclonal, 1:1000, Neomarkers, Fremont, CA), Mac-2 (rat monoclonal, 1:500, Cedarlane, Burlington, ON, Canada), GM130 (mouse monoclonal, 1:100, BD, Franklin Lakes, NJ), Rab7 (rabbit polyclonal, 1:100, Santa Cruz Biotechnology, Dallas, TX), microtubule-associated protein 2 (HM2, mouse monoclonal, 1:500, Sigma-Aldrich), ionized calcium-binding adapter molecule 1 (rabbit polyclonal, 1:200, Wako Pure Chemical Industries, Osaka, Japan), 2', $3^{\prime}$-cyclic-nucleotide $3^{\prime}$ phosphodiesterase (mouse monoclonal, 1:200, Covance, Princeton, NJ), SMI31 (mouse monoclonal, 1:1000, Covance), synaptophysin (mouse monoclonal, EMD Millipore), and 4 hydroxynonenal (mouse monoclonal, 1:200, Nikken Seil, Shizuoka, Japan).

\section{Western Blot Analysis}

Mice of both genotypes at the age of 12 weeks were deeply anesthetized with diethyl ether and decapitated, and then each tissue was dissected and lysed in radioimmunoprecipitation assay buffer $[50 \mathrm{mmol} / \mathrm{L}$ Tris- $\mathrm{HCl}$, pH 7.6; $150 \mathrm{mmol} / \mathrm{L} \mathrm{NaCl} ; 1 \%$ Triton X-100 (Nacalai Tesque, Kyoto, Japan); $0.5 \%$ sodium deoxycholate; $0.1 \%$ SDS] containing protease inhibitor cocktail (Nacalai Tesque) by means of a homogenizer (Polytron PT3100, Kinematica, Littau-Lucerne, Switzerland). After centrifuging at $10,500 \times g$ for 10 minutes at $4^{\circ} \mathrm{C}$, the protein concentration of the supernatants was determined by means of a microplate reader SpectraMax M2 (Molecular Devices Japan, Tokyo, Japan) by using bovine serum albumin as a standard. Proteins were separated on $10 \%$ or $15 \%$ SDS-polyacrylamide gels, transferred to polyvinylidene difluoride membranes (EMD Millipore), and incubated with 5\% skim milk in phosphate-buffered saline (PBS) with Tween 20 [135 mmol/L PBS containing $0.05 \%$ Tween 20 (Nacalai Tesque)] for 1 hour at room temperature. The membranes were incubated overnight with each primary antibody, washed in PBS with Tween 20, and further incubated with anti-mouse or rabbit IgG horseradish peroxidase conjugate (1:1000, Dako). After washing in PBS with Tween 20, the membranes were developed with chemiluminescent horseradish peroxidase substrate (Immobilon Western, EMD Millipore) and analyzed using the LAS-4000 luminescent image analyzer (Fujifilm, Tokyo, Japan). $\beta$-Actin was used as a loading control. Statistical analyses $(n=3)$ were performed using a Student's $t$-test in Excel (Microsoft, Redmond, WA). 


\section{Immunohistochemical Analysis}

For immunohistochemical studies, male mice of both genotypes at 12 and 32 weeks of age (total 12 mice) were deeply anesthetized with diethyl ether and perfused with $4 \%$ paraformaldehyde. The brain, heart, and liver were removed and postfixed overnight and then embedded in paraffin and sectioned. Sections $(5 \mu \mathrm{m}$ thick) were deparaffinized and treated with $1 \%$ hydrogen peroxide for 30 minutes, autoclaved at $105^{\circ} \mathrm{C}$ for 10 minutes, and then incubated with 5\% normal serum in PBS ( $\mathrm{pH}$ 7.4) for 1 hour at room temperature followed by incubation overnight at $4^{\circ} \mathrm{C}$ with each primary antibody. The sections were washed in PBS then incubated with biotinylated secondary antibodies diluted 1:500 in PBS containing 5\% normal serum. The sections were treated with the VECTASTAIN Elite ABC kit (Vector Laboratories, Burlingame, $\mathrm{CA}$ ) according to the manufacturer's protocol. Some sections were incubated with EnVision + System horseradish peroxidase-labeled polymer anti-rabbit or anti-mouse (Dako) as secondary antibodies. Sections were developed with $0.02 \% 3,3^{\prime}$-diaminobenzidine tetrahydrochloride solution containing $0.003 \%$ hydrogen peroxide. After visualization, sections were counterstained with hematoxylin.

For single or double immunofluorescent studies, sections were incubated with primary antibodies overnight, followed by secondary antibodies conjugated to Alexa Fluor 488 and/or 594 (1:200, Molecular Probes, Thermo Fisher Scientific, Eugene, OR) for 1 hour, then DAPI $(250 \mathrm{nmol} / \mathrm{L})$ for $5 \mathrm{mi}-$ nutes. Confocal microscopy was performed using the FluoView FV1000 confocal microscope system (Olympus, Tokyo, Japan). The percentage of intracellular particles that were immunoreactive for Lamp-2, Lamp-1, or Rab7 was counted in 100 particles of hippocampal large neurons for three candidates from each wild-type and Lamp-2-deficient mice groups.

\section{Fluorescein Isothiocyanate Lectin Staining for Glycoanalysis}

To identify the profiling of glycans for intracytoplasmic aggregates, we stained fluorescein isothiocyanate-conjugated lectins. Paraffin-embedded 4\% paraformaldehyde-fixed sections were deparaffinized and incubated with $3 \%$ bovine serum albumin in PBSfor 1 hour at room temperature followed by incubation overnight at $4^{\circ} \mathrm{C}$ with each fluorescein isothiocyanate-conjugated lectin for concanavalin A, succinyl concanavalin A, wheat germ agglutinin, Lens culinaris agglutinin, Psathyrella velutina lectin, Phaseolus vulgaris erythrolectin, Vicia villosa lectin, Galanthus nivalis lectin, or Bauhinia purpurea lectin (Sigma-Aldrich) diluted 1:500 in $3 \%$ bovine serum albumin in PBS. The sections were observed with a confocal laser scanning microscope (FluoView FV1000, Olympus).

\section{Electron Microscopic Analysis}

Both genotypes of male mice at the age of 8 and 34 weeks (total eight mice) were deeply anesthetized with dimethyl ether and perfused with $2 \%$ paraformaldehyde and $2 \%$ glutaraldehyde in $0.1 \mathrm{~mol} / \mathrm{L}$ phosphate buffer $(\mathrm{pH} 7.4)$. The brain and liver were removed, postfixed with the same fixative, and left overnight at $4^{\circ} \mathrm{C}$. The specimens were trimmed and washed with PBS, incubated in phosphate-buffered $1 \%$ osmium tetroxide for 1 hour, dehydrated in ethanol, and embedded in resin (Epon 812, TAAB Laboratories Equipment, Berkshire, UK). Ultrathin sections were mounted on copper grids and stained with uranyl acetate and lead citrate. The sections were observed using an H-7000 electron microscope (Hitachi, Tokyo, Japan) or Tecnai transmission electron microscope (FEI, Hillsboro, OR).

\section{Results}

\section{General Appearance of Lamp-2-Deficient Mice}

The body weights of Lamp-2-deficient mice were significantly reduced when compared with those of wild-type mice at 16 weeks of age (Supplemental Figure S1). Lamp-2deficient mice are reported to have increased mortality between 20 and 40 days of age. ${ }^{12}$ In our observation, life spans of the mice that survived $>40$ days were also shortened (Supplemental Figure S2).

\section{Localization of Lamp-2 in the CNS}

Lamp-2 protein is abundant in the liver, and to a lesser extent, in the heart and brain of wild-type mice at the age of 12 weeks (Figure 1A). Expression of Lamp-2 was lacking in the Lamp-2-deficient mice (Figure 1, A-E). Double immunohistochemical analysis revealed that immunoreactivity for Lamp-2 largely colocalized in granules with immunoreactivity for Lamp-1 (89.3\%), and some granules immunopositive for Lamp-2 colocalized with those for a late endosome marker, Rab7 (10.7\%) (Figure 1, F and G). In the CNS, Lamp-2 was expressed ubiquitously in the neurons (microtubule-associated protein 2) (Figure 1, H-J), astrocytes (glial fibrillary acidic protein) (Figure 1, K-M), microglia (ionized calcium-binding adapter molecule 1) (Figure 1, N-P), and oligodendrocytes $\left(2^{\prime}, 3^{\prime}\right.$-cyclic-nucleotide $3^{\prime}$-phosphodiesterase) (Figure 1, Q-S), showing relatively prominent staining in large neurons (Figure 1D).

\section{Morphological and Functional Changes in Lysosomes in Lamp-2-Deficient Mice}

To study the structural and immunohistochemical changes in lysosomes, expression of another lysosomal membrane protein, Lamp-1 and a lysosomal aspartic proteinase, we examined cathepsin D. Western blot analysis showed that expression of Lamp-1 and cathepsin D was significantly increased in the brain of Lamp-2-deficient mice (Figure 2, A and B). Both Lamp-1 and cathepsin D-immunoreactive lysosomes were enlarged, especially in the large neurons of Lamp-2-deficient mice (Figure 2, $\mathrm{C}-\mathrm{H}$ ). 

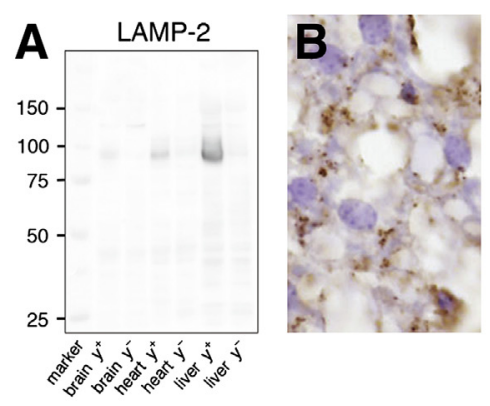

$\mathbf{F}$
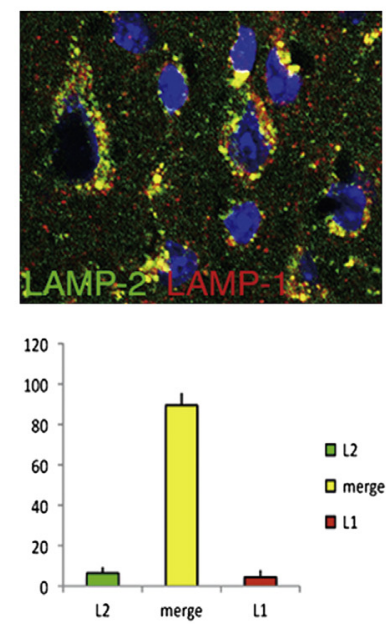
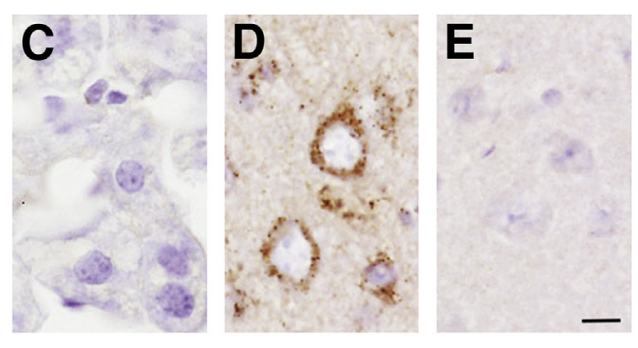

G
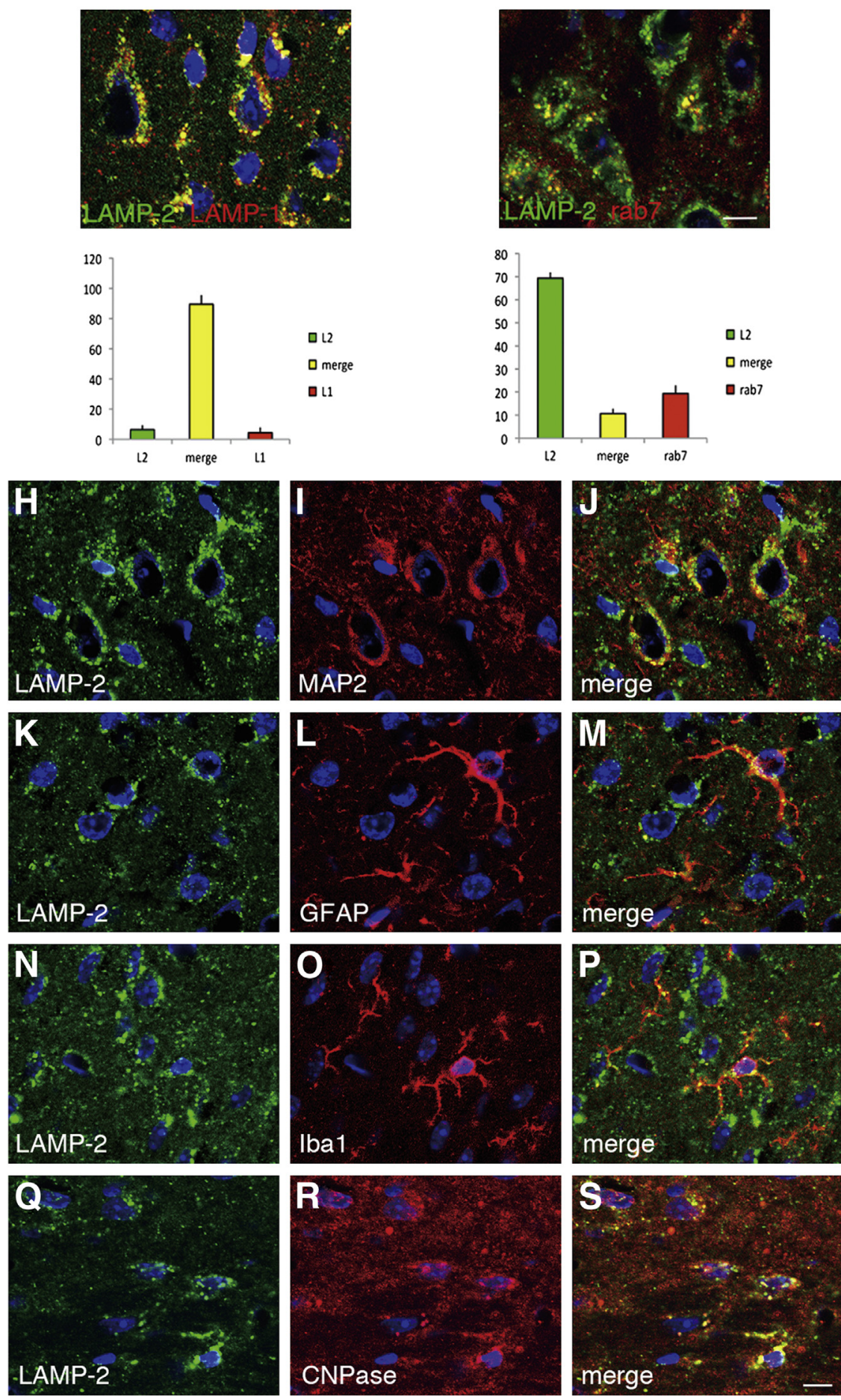
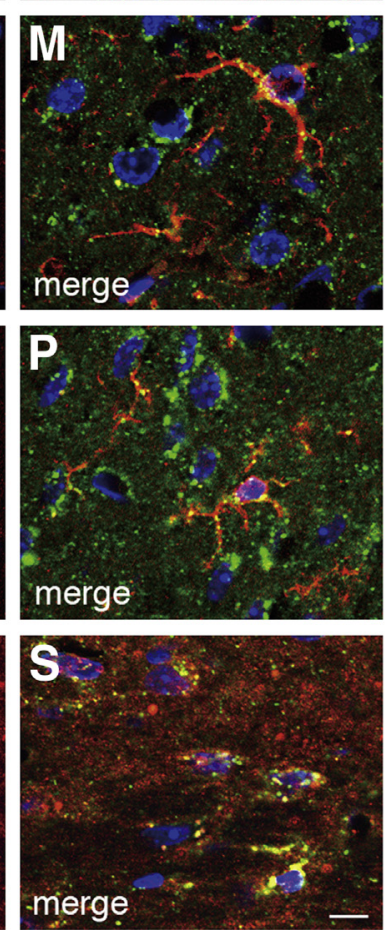

Figure 1 Lysosome-associated membrane protein-2 (Lamp-2) is expressed mainly in the lysosomes and enriched in the large neurons of the brain. A: Western blot analysis of Lamp-2 with lysates from the brain ( $30 \mu \mathrm{g}$ per lane), heart (10 $\mu \mathrm{g}$ per lane), and liver (10 $\mu \mathrm{g}$ per lane) in wild-type and Lamp-2deficient mice. The immunoreactive band for Lamp-2 is undetectable in Lamp-2-deficient mice. B-E: Immunoreactivity for Lamp-2 is observed in the liver (B) and neocortex (D) of the wild-type mice, whereas little immunoreactivity is seen in the liver (C) and neocortex (E) of the Lamp-2-deficient mice. $\mathbf{F}$ and $\mathbf{G}$ : Double immunohistochemical analysis reveals that Lamp-2 colocalizes with Lamp-1 (F; 89.3\%) and with Rab7 (G; 10.7\%). H-S: Lamp-2 partially colocalizes with microtubule-associated protein $2(\mathrm{MAP2} ; \mathbf{H}-\mathbf{J})$, glial fibrillary acidic protein (GFAP; $\mathbf{K}-\mathbf{M}$ ), ionized calcium-binding adapter molecule 1 (Iba1; $\mathbf{N}-\mathbf{P}$ ), and $2^{\prime}, 3^{\prime}$-cyclic-nucleotide $3^{\prime}$-phosphodiesterase (CNPase; $\mathbf{Q}-\mathbf{S})$. Scale bars: $10 \mu \mathrm{m}$. 
A

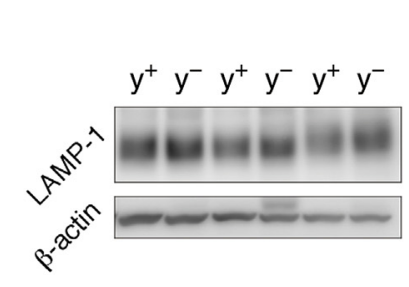

B

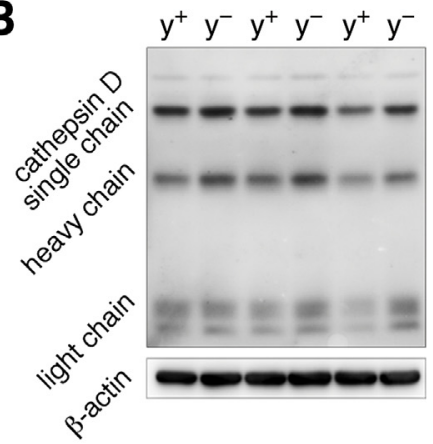

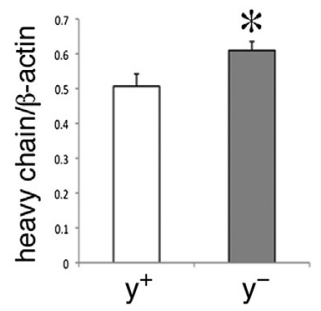
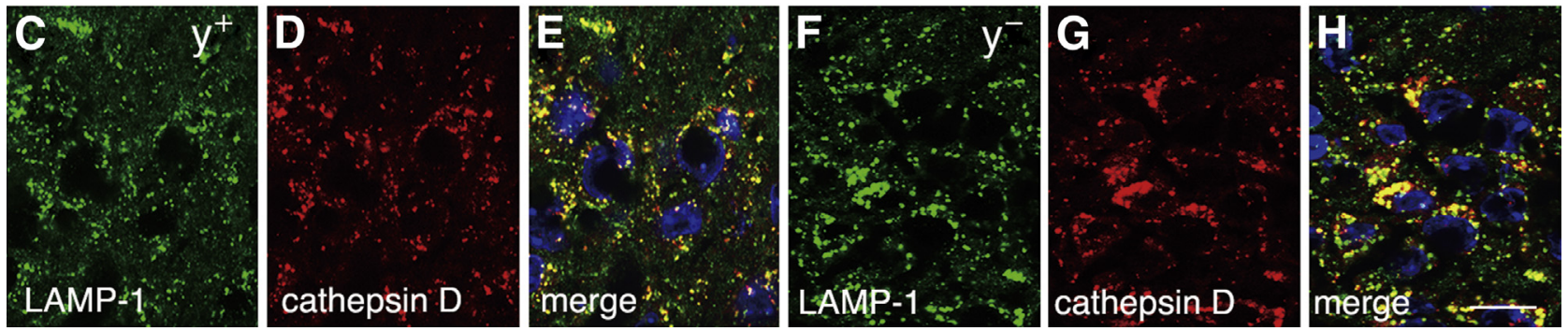

Figure 2 Expression of lysosome-associated membrane protein-2 (Lamp-1) and cathepsin D increases in the brain of Lamp-2-deficient mice. A and B: Western blot analysis reveals that expression of both Lamp-1 (A) and cathepsin D (B) significantly increases in the brain of Lamp-2-deficient mice ( $\mathrm{y}^{-}$) compared with in wild-type mice $\left(\mathrm{y}^{+}\right)$. Each value represents the means \pm SEM. C-H: Double immunohistochemical analysis shows Lamp-1 and cathepsin D-immunoreactive lysosomes are enlarged in the CA3 of Lamp-2-deficient mice (12 weeks $\mathbf{F}-\mathbf{H}$ ). ${ }^{*} P<0.05$. Scale bar $=10 \mu \mathrm{m}$.

Electron microscopic observations showed primary lysosomes in wild-type mice (Figure 3, A and D) and accumulation of glycogen granules and membranous materials in lysosomes of the liver in Lamp-2-deficient mice at the age of 8 weeks (Figure 3, B and C). Although morphological changes in lysosomes were also observed in the hippocampal neurons of Lamp-2-deficient mice, glycogen granules did not accumulate in lysosomes (Figure 3, E and F). Lipofuscin in the large neurons was sometimes seen in the 34-week-old wild-type mice (Figure 3G). In addition to lipofuscin, vesiclecontaining structures were seen in the cytoplasm of hippocampal neurons in Lamp-2-deficient mice (Figure 3H). Various materials accumulated not only in neurons but also in other cell types in the CNS of Lamp-2-deficient mice. Aggregates of membrane structures were detected in astrocytes (Figure 3I), whereas electron-dense materials packed in large granules that contained small electron-dense and -lucent vesicles were present in pericytes (Figure 3J).

To identify the properties of lysosomal accumulation, we performed immunohistochemical analysis for ubiquitin (Figure 4, A-D) and lectin staining (Figure 4, E and F). Ubiquitin-immunoreactive aggregates were found in the neuronal perikarya of the neocortex and hippocampal CA3 region (Figure 4, B and D). At confocal laser scanning microscopy, autofluorescence was detected in granular structures, some of which colocalized with positive staining for concanavalin A that interacts with D-mannose and D-glucose; these appeared more abundantly in the hippocampal CA3 neurons of Lamp-2-deficient mice than in those of wild-type mice (Figure 4, E and F).

\section{Alterations of the Golgi Apparatus in Large Neurons}

Besides morphological and functional changes in lysosomes, the structure of the Golgi apparatus was altered in the Lamp-2-deficient mice (Figure 5). Immunoreactivity for GM130, a Golgi matrix protein, increased in large neurons of Lamp-2-deficient mice at the age of 12 weeks (Figure 5, A and B). Ultrastructurally, the cisternae of the Golgi lamellae were dilated at the age of 8 weeks, and some cisternae took a circular form at the age of 32 weeks (Figure 5, C-F).

\section{Cell-Type Specific Changes in Expression for LC3 in Lamp-2-Deficient Mice}

Because skeletal muscle biopsy results for Danon disease exhibit autophagic vacuolar myopathy, ${ }^{3,4}$ expression of LC3, a macroautophagy marker protein, was examined. Expression levels of LC3-II, a membrane-bound type, were significantly increased in the liver of the Lamp-2-deficient mice compared with that in control mice, as evidenced by Western blot analysis (Figure 6A) $(P<0.05)$, whereas expression levels of LC3-II were similar in the brain of both phenotypes (Figure 6B). Immunoreactivity for LC3 was detected in large granules in the cardiac myocytes and hepatocytes of Lamp-2-deficient mice (Figure 6, C-F). Electron micrographs showed a large amount of autophagic vacuoles and dense bodies in the liver of Lamp-2-deficient mice (Figure 6G). In the brain, expression of LC3 in Lamp2 -deficient mice was similar to that in wild-type mice 

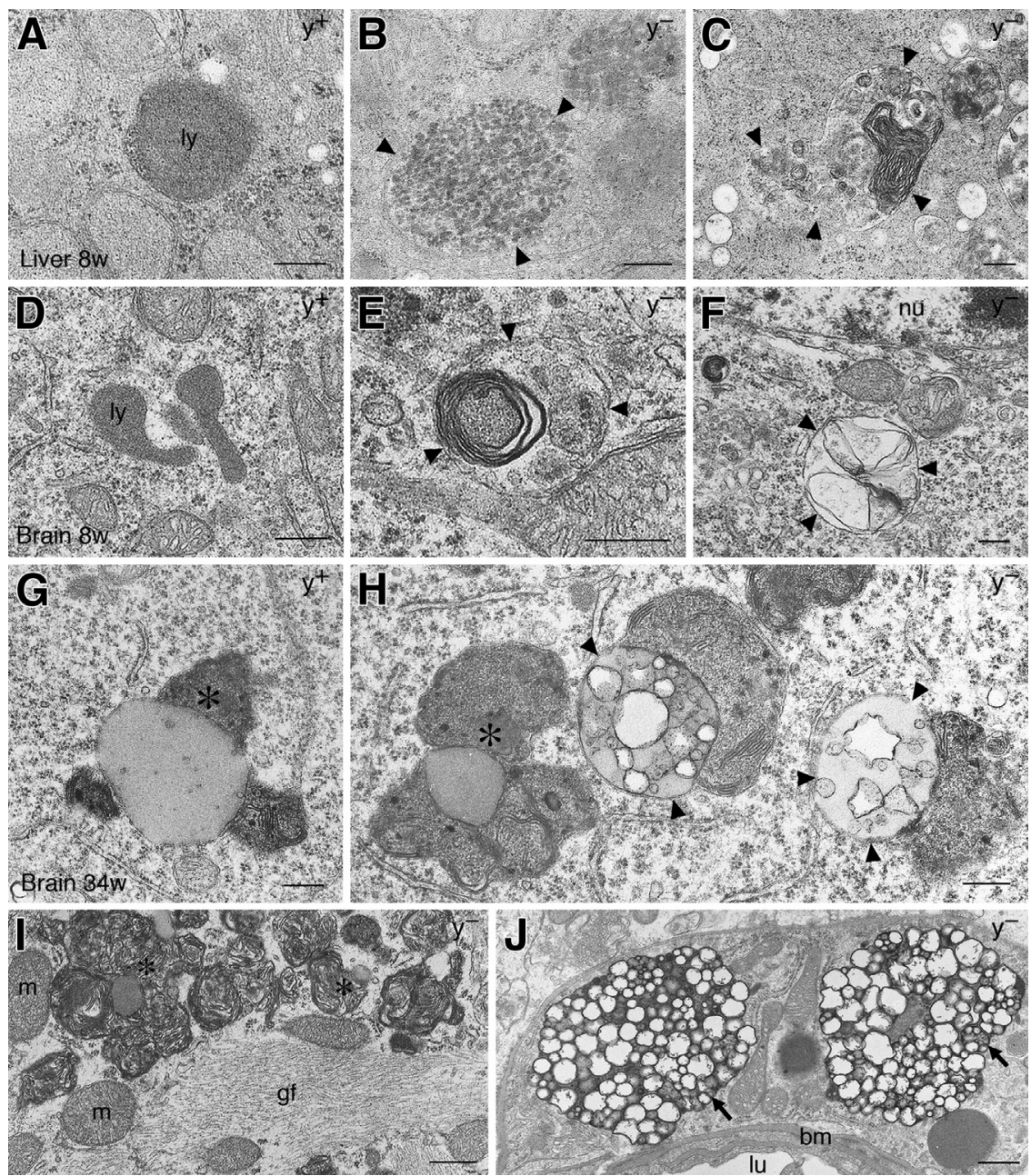

Figure 3 Ultrastructure of lysosomes and accumulation of various materials in the liver at 8 weeks (w) $(\mathbf{A}-\mathbf{C})$ and brain at 8 weeks $(\mathbf{D}-\mathbf{F})$ and 34 weeks $(\mathbf{G}-\mathbf{J})$ in wild-type mice $\left(\mathrm{y}^{+} ; \mathbf{A}, \mathbf{D}\right.$, and $\left.\mathbf{G}\right)$ and Lamp-2-deficient mice $\left(\mathrm{y}^{-} ; \mathbf{B}, \mathbf{C}, \mathbf{E}, \mathbf{F}\right.$, and $\left.\mathbf{H}-\mathbf{J}\right)$. A-C: Lysosomes (ly) appear as electron-dense organelles in the liver of wild-type mice. Accumulations of glycogen (arrowheads, B) and membranous materials (arrowheads, C) in lysosomes are observed in the liver of Lamp-2-deficient mice. D-F: In contrast to lysosomes in neuronal cytoplasm of 8-week-old wild-type mice, lysosomal changes with membranous accumulations are found in the neurons of Lamp-2deficient mice (arrowheads, $\mathbf{E}$ and $\mathbf{F}$ ). G-J: In the brain at the age of 34 weeks, lipofuscin is observed in hippocampal CA3 neurons of both wild-type and Lamp-2-deficient mice (asterisk, $\mathbf{G}$ and $\mathbf{H}$ ). In addition, vesicle-containing materials (arrowheads, H) are seen in the cytoplasm of neurons in Lamp-2deficient mice. Membranous materials in astrocytes (asterisks, I) and electron-dense materials with small vesicles in pericytes (arrows, J) are also accumulated. bm, basement membrane; gf, glial filaments; lu, lumen; $m$, mitochondria; nu, nucleus. Scale bars: $250 \mathrm{~nm}$ (A-H); $500 \mathrm{~nm}$ (I and J).
(Figure 6, H and I) except for in the substantia nigra pars reticulata, where some LC3-immunoreactive large granular structures (Figure 6, J and $\mathrm{K}$ ) and autophagic vacuolecontaining axons were observed (Figure 6L). Although Western blot analysis for LC3-II with use of whole brain lysates did not show any difference between wild-type and Lamp-2-deficient mice (Figure 6B), analysis with midbrain lysates revealed increased expression of LC3-II in Lamp2-deficient mice (Supplemental Figure S3A). Irrespective of such findings in the substantia nigra, neuronal loss of dopaminergic neurons was not observed with tyrosine hydroxylase staining (data not shown).

\section{Midbrain Pathology with Extensive Glial Reactions}

To further investigate the midbrain pathology, we performed immunohistochemical analysis for $\alpha$-synuclein, one of the most important CMA substrates, and relevant proteins (Figure 7). First, we confirmed that the antibody for $\alpha$-synuclein would not cross-react with $\beta$ - or $\gamma$-synuclein (data not shown). Although expression of $\alpha$-synuclein (Figure $7 \mathrm{M}$ ) and a key regulator for CMA, Hsc70 (Supplemental Figure S3B), in the brain of Lamp-2-deficient mice was similar to that of wild-type mice, immunohistochemical studies revealed that large dotted structures positive for $\alpha$ synuclein were found in the substantia nigra pars reticulata (Figure 7, A-D). Expression of $\alpha$-synuclein in the dotted structures was not seen after proteinase $\mathrm{K}$ treatment (Supplemental Figure S4). Phosphorylated $\alpha$-synuclein was not detected in the Lamp-2-deficient brain (data not shown). The structures were colocalized in part with SMI31, synaptophysin, Mac-2, and 4 hydroxynonenal (Figure 7, N-Q), suggesting that axons and activated microglia are associated with lipid peroxidation. In the substantia nigra, extensive reactive astrocytosis (Figure $7, \mathrm{E}-\mathrm{H}$ ) and activated microglial infiltration (Figure 7, I-L) were observed.

\section{Discussion}

\section{Expression of Lamps in the CNS}

LAMPs are major components of lysosome membranes. In our observation, Lamp-2 was ubiquitously distributed to different cell types and enriched in the large neurons in the CNS. The majority of Lamp-2-immunoreactive vesicles colocalized with Lamp-1 in these large neurons. Although 


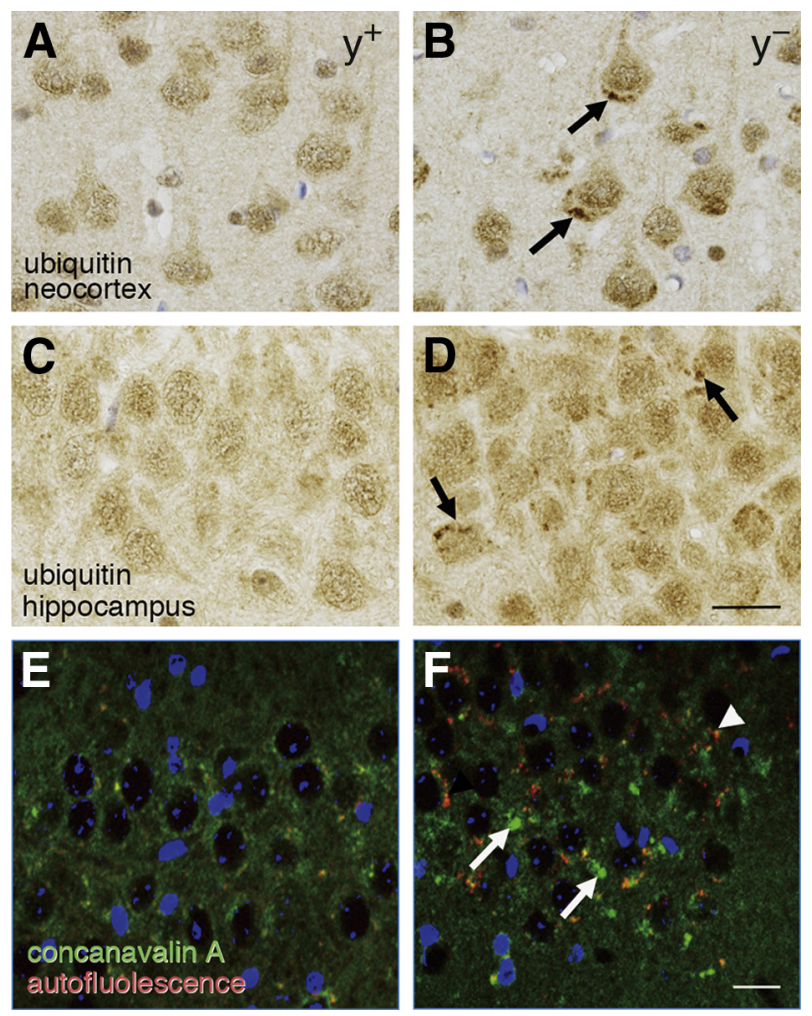

Figure 4 Expression of ubiquitin and concanavalin $\mathrm{A}$ increases in the large neurons of Lamp-2-deficient mice at the age of 32 weeks. A-D: Immunohistochemical images for ubiquitin in the neocortex (A and $\mathbf{B})$ and hippocampal CA3 (C and D) in wild-type $\left(\mathrm{y}^{+} ; \mathbf{A}\right.$ and $\mathbf{C}$ ) and Lamp2-deficient $\left(\mathrm{y}^{-} ; \mathbf{B}\right.$ and $\left.\mathbf{D}\right)$ mice reveals that large neurons in Lamp2-deficient mice contain ubiquitin-immunoreactive aggregates (arrows, B and D). E and F: Concanavalin A staining (green; arrows, F) and autofluorescence (red; arrowhead, F) positive deposits in the hippocampal CA3 are abundant in Lamp-2-deficient mice (F) compared with those in wildtype mice (E). Scale bar $=20 \mu \mathrm{m}$.

Lamp-1-deficient mice exhibited mild gliosis and altered cathepsin D immunoreactivity in the brain with normal lysosomal morphology, ${ }^{14}$ double deficiency of both Lamp-1 and Lamp-2 is embryonic lethal. ${ }^{15}$ Because expression of Lamp-1 was elevated in the brains of Lamp-2-deficient mice, it is likely that these two proteins are interdependent in CNS neurons. Therefore, phenotypes of Lamp-2deficient mice may indicate a specific function for Lamp-2.

\section{Lamp-2-Deficient Mice as a Model of Lysosomal Storage Disease}

Two-thirds of lysosomal storage diseases involve the CNS; however, their exact contribution to mental retardation remains unknown. ${ }^{16}$ LAMP-2-deficient human Danon disease was first diagnosed as a glycogen storage disease because glycogen granules accumulated in the muscle. ${ }^{2} \mathrm{We}$ observed accumulations of electron-dense materials and ubiquitin-immunoreactive aggregates in the neuronal cytoplasm of the Lamp-2-deficient brain. Because various shaped materials accumulated in the different cell types of
Lamp-2-deficient mice, these findings are likely not the consequence of deficiency of a single lysosomal enzyme but a disorder of enzyme trafficking or targeting or defective function of nonenzymatic lysosomal proteins. Results from functional studies have revealed that LAMP-2 deficiency leads to impaired recycling of 46-kDa mannose 6-phosphate receptors and partial mistargeting of lysosomal enzyme. ${ }^{17}$ LAMP-2 also plays a critical role in endosomal cholesterol transport. ${ }^{18}$ Our morphological studies are consistent with those in these reports.

Lectin staining revealed that intracellular aggregates were positive for concanavalin A, which binds D-mannose and
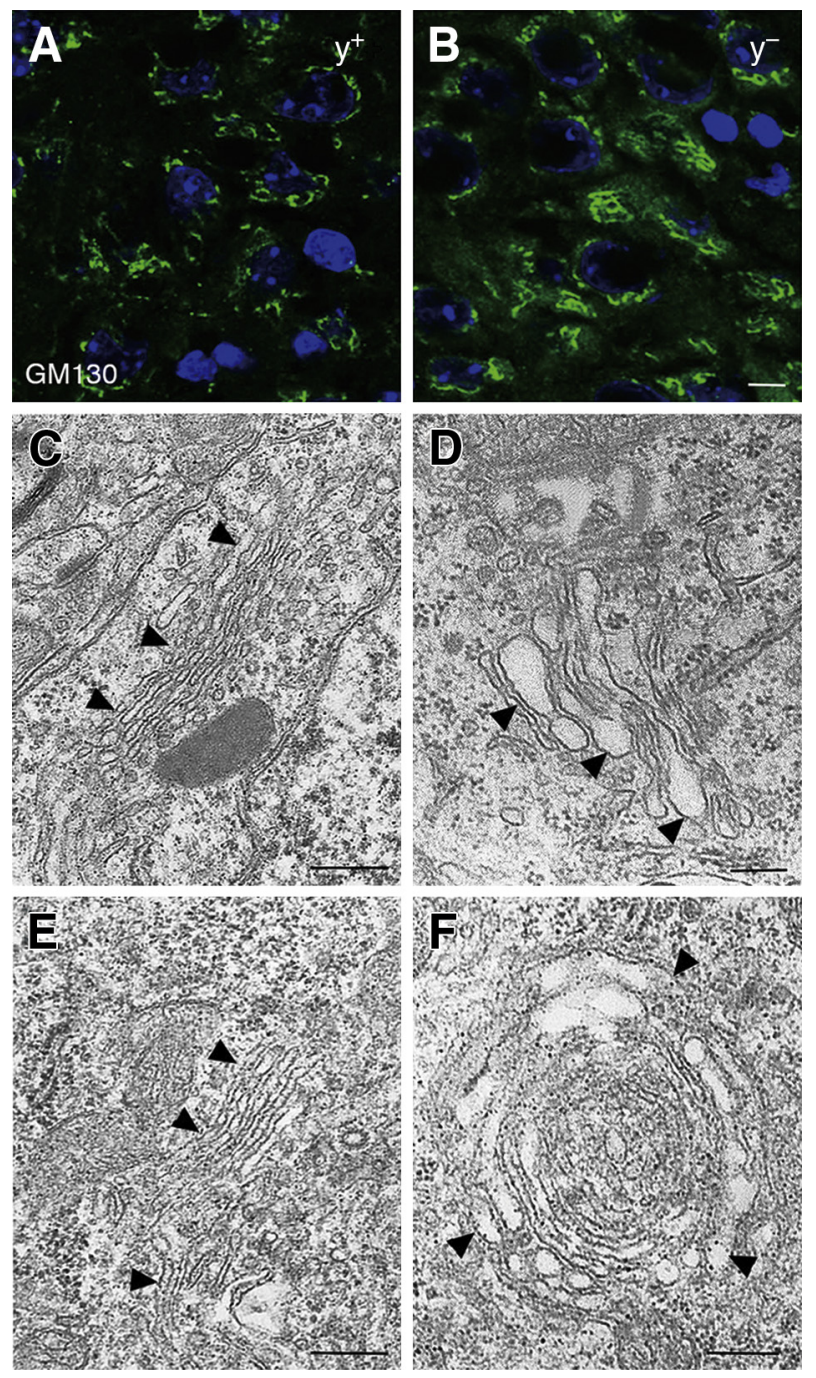

Figure 5 Structure of Golgi apparatus is altered in the neurons of Lamp-2-deficient mice. A and B: Immunoreactivity for GM130 is more abundant in the hippocampal pyramidal neurons of Lamp-2-deficient mice $\left(\mathrm{y}^{-}\right)$than that in wild-type mice $\left(\mathrm{y}^{+}\right)$. C-F: Electron micrographs show that the Golgi apparatus appears as thin lamellar structures in the CA3 neurons of wild-type mice ( 8 weeks, C; 32 weeks, E; indicated by arrowheads). In the neurons of Lamp-2-deficient mice, dilatation of cisternae ( 8 weeks, $\mathbf{D}$; indicated by arrowheads) and circular structures (32 weeks, F; indicated by arrowheads) are observed. Scale bars: $10 \mu \mathrm{m}$ (A and $\mathbf{B}) ; 250 \mathrm{~nm}(\mathbf{C}-\mathbf{F})$. 

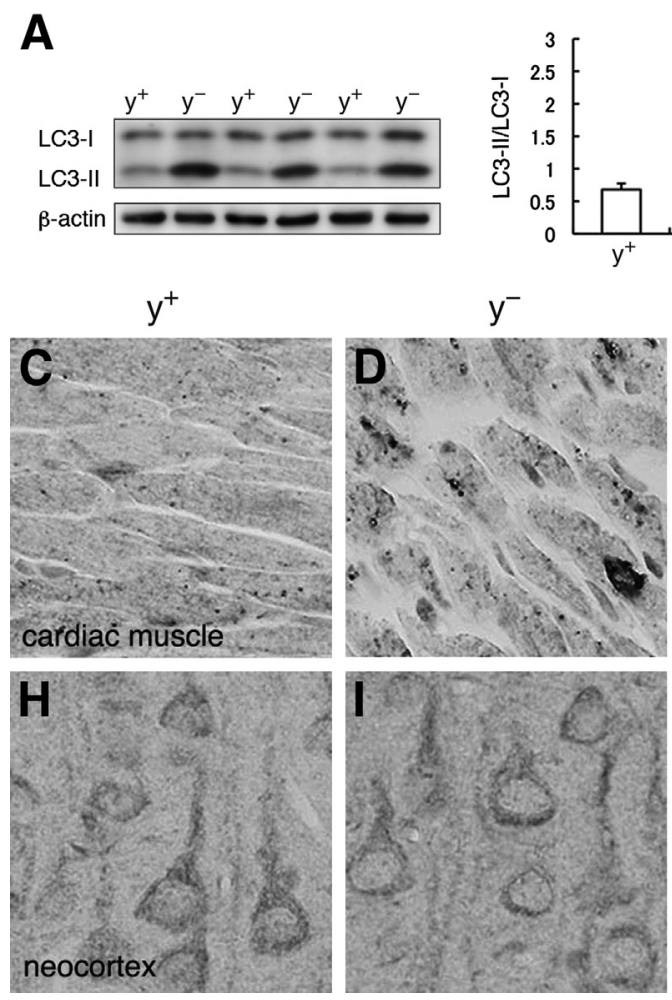
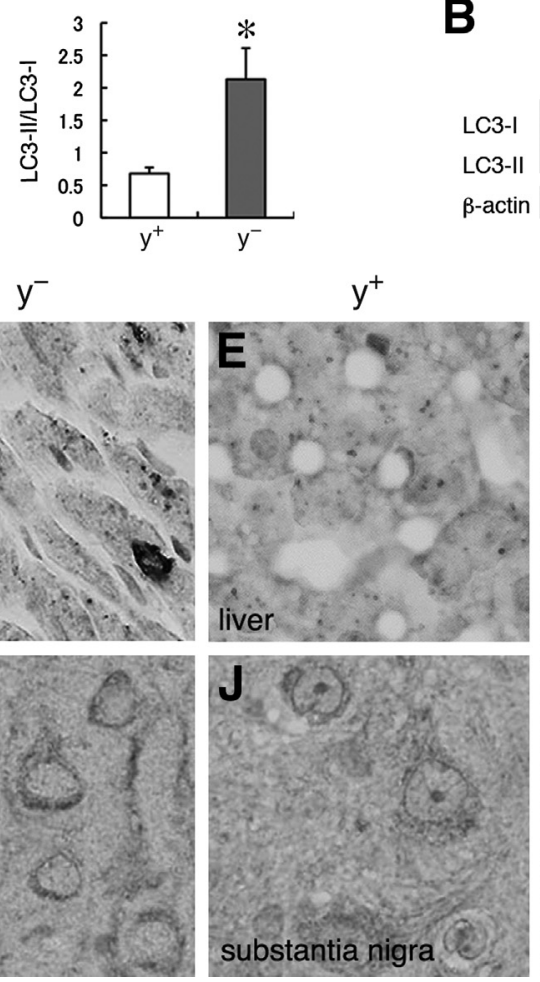

B
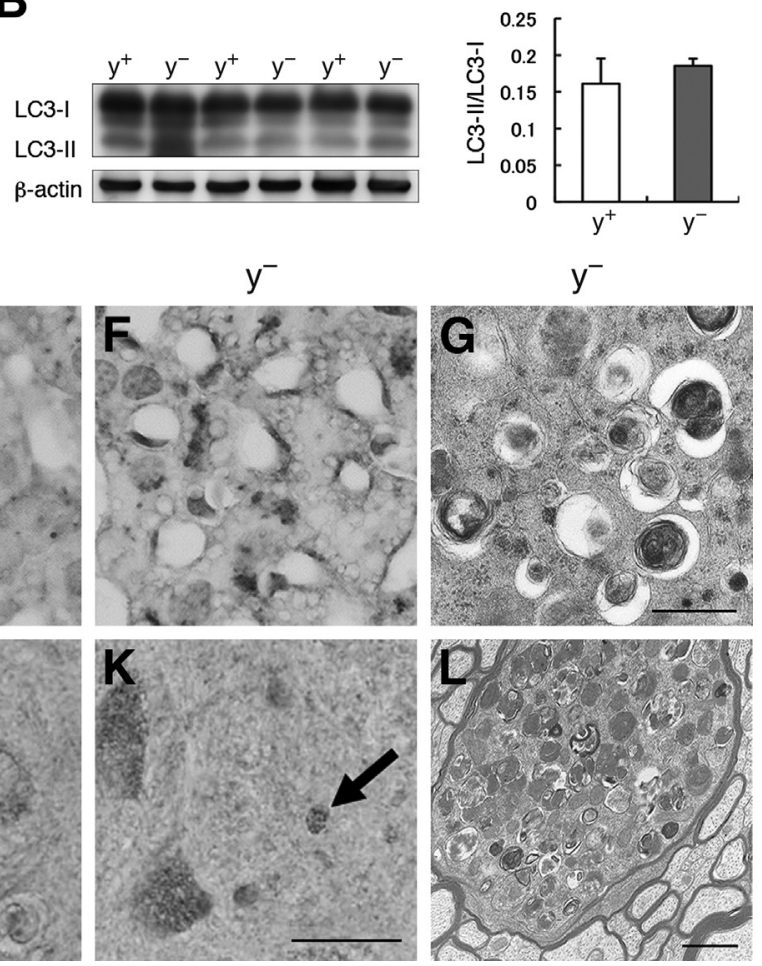

Figure 6 Macroautophagy is less affected in the brain of Lamp-2-deficient mice at the age of 12 weeks. A and B: Western blot analysis reveals that expression of membrane-bound type light chain 3 (LC3)-II significantly increases in the liver of Lamp-2-deficient mice (A); however, there is no significant change of LC3 expression in the central nervous system (CNS) (B). $\beta$-Actin was used as a loading control. $\mathbf{C}-\mathbf{F}$ and $\mathbf{H}-\mathbf{K}$ : Immunohistochemical analysis for LC3 in the cardiac muscle (C and $\mathbf{D})$, liver $(\mathbf{E}$ and $\mathbf{F})$, cerebral neocortex ( $\mathbf{H}$ and $\mathbf{I})$, and substantia nigra $(\mathbf{J}$ and $\mathbf{K})$ of wild-type mice $\left(\mathrm{y}^{+}\right)$and Lamp2-deficient mice $\left(\mathrm{y}^{-}\right)$. In the Lamp-2-deficient mice, LC3-immunoreactive deposits are found in cardiac muscle (D) and hepatocytes (F); however, such immunoreactivity is not found in the CNS (I and K), except for LC3-positive large granular structures in the substantia nigra pars reticulata (arrow, K). $\mathbf{G}$ and $\mathbf{L}$ : Electron micrographs show accumulations of autophagic vacuoles and dense bodies in the hepatocytes $(\mathbf{G})$ and axons of the substantia nigra (L) in Lamp2-deficient mice. Each value represents the means \pm SEM. ${ }^{*} P<0.05$. Scale bars: $20 \mu \mathrm{m}(\mathbf{C}-\mathbf{F}, \mathbf{H}-\mathbf{K}) ; 500 \mathrm{~nm}(\mathbf{G}) ; 1 \mu \mathrm{m}(\mathbf{L})$.

D-glucose. Virtanen et al ${ }^{19}$ examined storage material in cultured fibroblasts by specific lectin binding in several lysosomal storage diseases and found that concanavalin A was positive for the materials in I-cell disease, which is a deficiency of phosphotransferase in the Golgi apparatus. In addition to the lysosomal changes, dysfunction of intracellular organelles, including the mitochondria, endoplasmic reticulum, and Golgi apparatus, has been described in lysosomal storage diseases. ${ }^{16}$ Large neurons of Lamp-2-deficient mice showed increased immunoreactivity for GM130 and morphological changes in the cisternae of Golgi lamellae. Accumulation of GM130 leads to alterations of Golgi ribbon architecture. ${ }^{20}$ Collectively, these findings in the CNS, in addition to growth retardation and low survival rate beyond postnatal day 40 (Supplemental Figures S1 and S2), are consistent with those of lysosomal storage disease. The main neuropathological feature-accumulation of lysosomes-is similar to that in human Danon disease. ${ }^{5}$

\section{Region-Specific Differences in Macroautophagy}

A large amount of autophagic vacuoles were found in the parenchymal cells of the various visceral organs both in
Danon disease and Lamp-2-deficient mice. ${ }^{1,12}$ Moreover, in the present study, we confirmed the elevation of autophagic activity in the heart and liver of Lamp-2-deficient mice. Multiple functions of LAMPs have been suggested so far: cholesterol traffic, ${ }^{15}$ fusion of lysosomes with phagosomes, ${ }^{21}$ and major histocompatibility complex class II antigen presentation. ${ }^{22}$ Expression of LAMP-2 is also related to pathological processes such as neoplasms and inflammation, ${ }^{23-25}$ although few experimental data on LAMP-2 have been shown in neuronal cells.

In the CNS, autophagic vacuoles were not observed in neurons except for some axons in the substantia nigra. Such cell-type specific alterations in the Lamp-2-deficient mice suggest that Lamp-2 may have distinct functions in each tissue or cell type. Constitutive autophagy is important in the CNS because lack of autophagy-related protein 7 or autophagy-related protein 5 in CNS tissue causes neuronal changes with ubiquitin-positive inclusion bodies. ${ }^{26,27}$ It is uncertain why neurons do not show many autophagic vacuoles in the Lamp-2-deficient brains. Neurons may have protective mechanisms against excessive autophagic processes. Another possible mechanism may be that Lamp-2 has no effects on autophagosomes in neurons. 

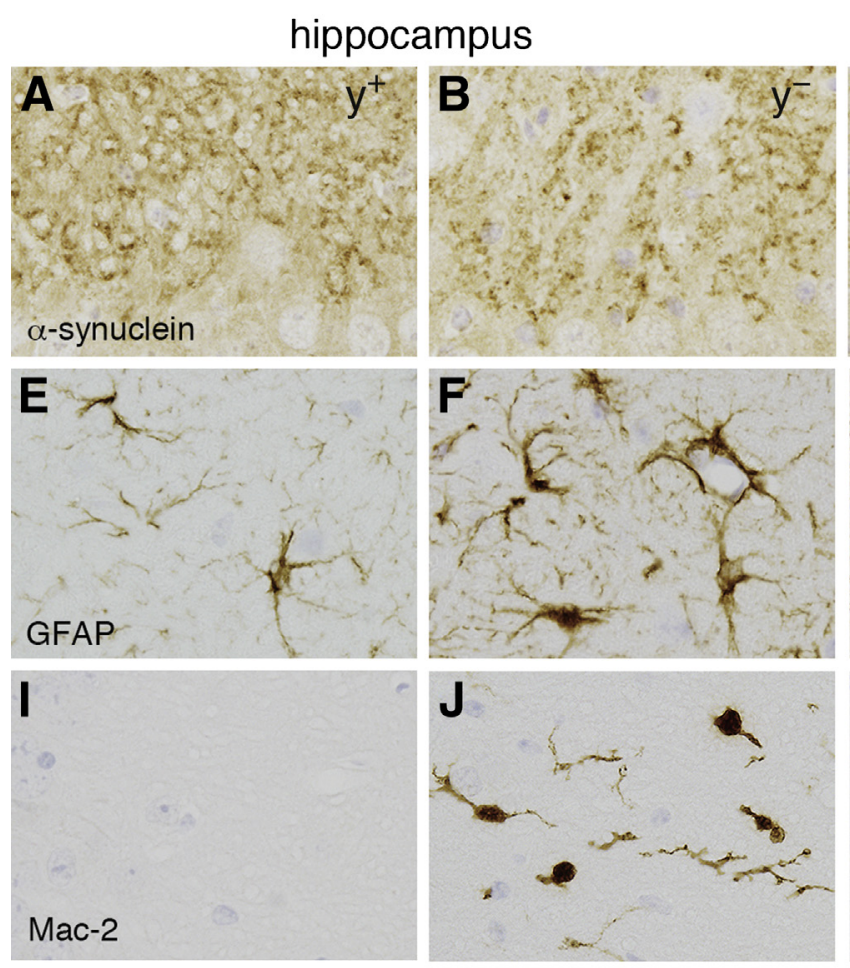

\section{substantia nigra}
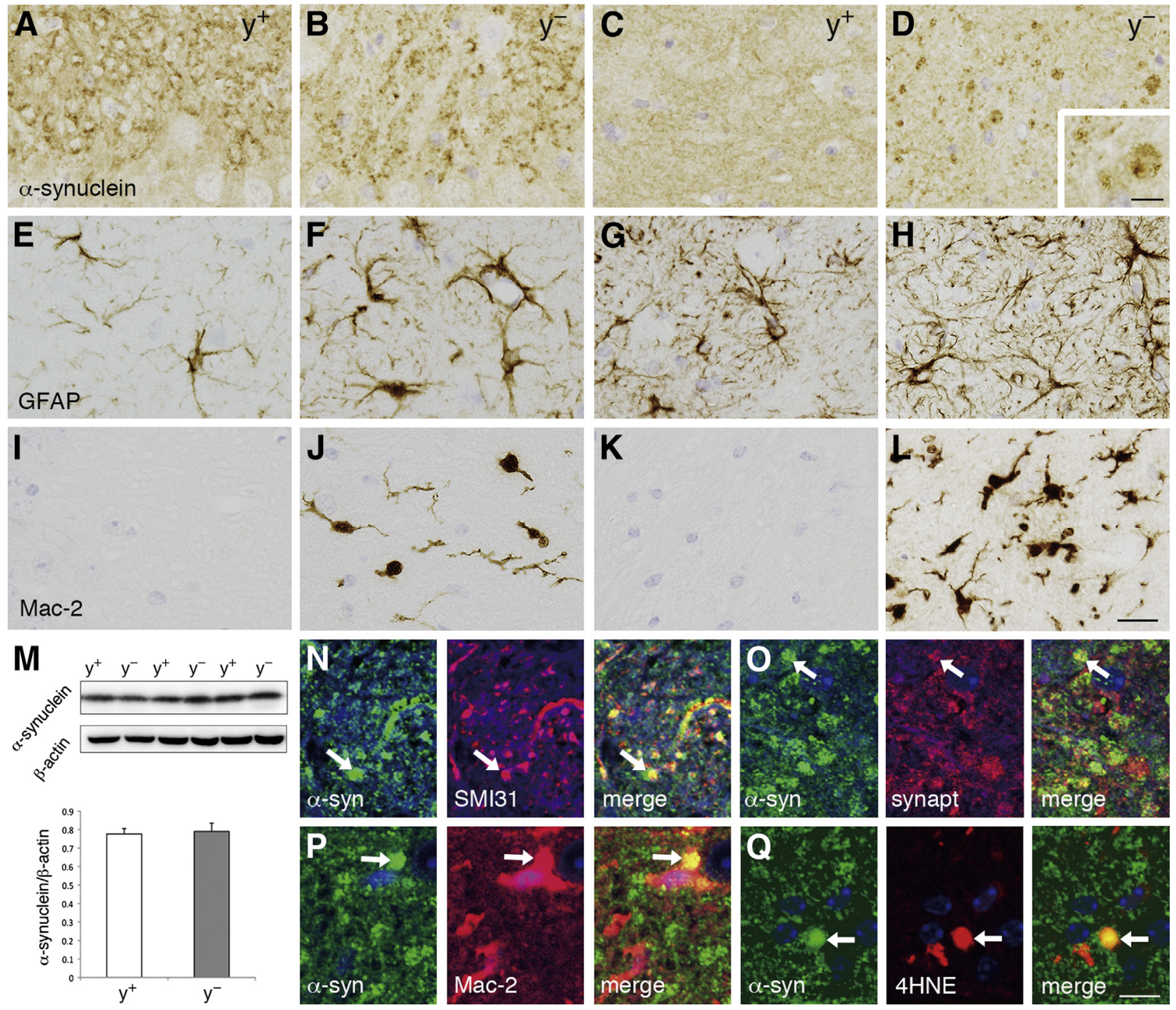

Figure $7 \quad \alpha$-Synuclein-immunoreactive structures with extensive glial changes and oxidative stress are seen in the substantia nigra at the age of 12 weeks. A-L: Immunohistochemical analysis for $\alpha$-synuclein (A-D), glial fibrillary acidic protein (GFAP; E-H), and Mac-2 (I-L) in the hippocampus (A, B, E, F, I, and J) and substantia nigra (C, D, G, H, K, and $\mathbf{L})$. $\alpha$-Synuclein-immunoreactive structures are found in the substantia nigra (D; inset, D). Extensive infiltration of GFAP-positive reactive astrocytes $(\mathbf{F}$ and $\mathbf{H})$ and Mac-2-positive activated microglia $(\mathbf{J}$ and $\mathbf{L}$ ) are seen in the substantia nigra and to a lesser extent in the hippocampus of Lamp-2-deficient mice. M: Western blot analysis for $\alpha$-synuclein in the brain shows no significant changes between wild-type and Lamp-2deficient mice. $\beta$-Actin is used as a loading control. $\mathbf{N}-\mathbf{Q}$ : Double immunofluorescence for $\alpha$-synuclein ( $\alpha$-syn; green) and SMI31 (N, red), synaptophysin (synapt; $\mathbf{0}$, red), Mac-2 (P, red), and 4 hydroxynonenal (4HNE; $\mathbf{Q}$, red) reveals colocalization of $\alpha$-synuclein and each protein ( $\mathbf{N}-\mathbf{Q}$, arrows). Scale bars: $20 \mu \mathrm{m}$ $(\mathbf{A}-\mathbf{L}) ; 10 \mu \mathrm{m}$ (inset, $\mathbf{D}$, and $\mathbf{N}-\mathbf{Q})$.

\section{Evidence of Midbrain Pathology Associated with Excessive Glial Reactions and Lipid Peroxidation}

We found intense astrocytic and microglial reactions in the substantia nigra and hippocampus of Lamp-2-deficient mice. Glial cells are also involved primarily in lysosomal storage diseases. ${ }^{28}$ Accumulation of membranous materials was found in the astrocytes of Lamp-2-deficient mice (Figure 3I). Relationships between lysosomal disease and Parkinson disease, as well as oxidative stress, have been suggested. ${ }^{29,30}$ Lysosomal dysfunction owing to LAMP-2 deficiency may cause lipid peroxidation, which enhances midbrain pathology; however, in Lamp-2-deficient mice, proteinase $\mathrm{K}$-resistant $\alpha$-synuclein did not accumulate, and a loss of dopaminergic neurons was not obvious.

\section{Selective Degradation in the Lysosomes via Lamp-2 Subtypes}

$\alpha$-Synuclein is one of the most important substrates for CMA, and impaired degradation has been implicated in Parkinson disease. ${ }^{31}$ Although some axonal swelling and 
activated microglial cells were immunoreactive for $\alpha$-synuclein, Western blot analysis for $\alpha$-synuclein with whole brain or midbrain homogenates did not show any difference between wild-type and Lamp-2-deficient mice. Moreover, phosphorylated $\alpha$-synuclein was not expressed in Lamp-2-deficient brains. Glyceraldehyde-3-phosphate dehydrogenase, another CMA substrate, also did not increase in Lamp-2-deficient mice. ${ }^{10} \mathrm{CMA}$ is activated during oxidative stress, ${ }^{32}$ and protein degradation in vivo has an alternative pathway; eg, $\alpha$-synuclein is also degraded by macroautophagy, the ubiquitin-proteasome system, ${ }^{33}$ and other proteases such as calpains, neurosin, and metalloproteinases. ${ }^{34}$ Although glyceraldehyde-3-phosphate dehydrogenase is known as a CMA substrate, 4 hydroxynonenal-modified glyceraldehyde-3-phosphate dehydrogenase could also be degraded by cathepsin $\mathrm{G}^{35}$ Therefore, a decrease in CMA activity owing to Lamp-2 deficiency could be compensated for by constitutive autophagy or the ubiquitinproteasome system in the CNS of Lamp-2-deficient mice. Another possible explanation may be that unknown receptors are involved in CMA. LAMP-2C is mainly expressed in neurons in the CNS and mediates RNautophagy and DNautophagy. ${ }^{10,11}$ Degradation of nucleic acids, in particular RNA, may be important in maintaining the neuronal environment. Another subtype, LAMP-2B is enriched in the liver and skeletal muscle. Because a patient with a frameshift of exon $9 b$ shows full symptoms of Danon disease, including mental retardation, the function of LAMP-2B is crucial for Danon disease, ${ }^{1}$ although the role of LAMP-2B in the CNS is unknown. Further investigation is required for understanding the specific function of each LAMP-2 subtype in vivo.

\section{Acknowledgments}

We thank Drs. Kiyomitsu Oyanagi, Kinuko Suzuki, and Koh Furuta for useful discussions, Drs. Paul Saftig and Judith Blanz for providing Lamp-2-deficient mice, Chihana Kabuta, Yohei Fujimoto, and Osamu Aizawa for technical assistance, and Robert Debold for editing the manuscript.

\section{Supplemental Data}

Supplemental material for this article can be found at http://dx.doi.org/10.1016/j.ajpath.2015.02.015.

\section{References}

1. Nishino I, Fu J, Tanji K, Yamada T, Shimojo S, Koori T, Mora M, Riggs JE, Oh SJ, Koga Y, Sue CM, Yamamoto A, Murakami N, Shanske S, Byrne E, Bonilla E, Nonaka I, DiMauro S, Hirano M: Primary LAMP-2 deficiency causes X-linked vacuolar cardiomyopathy and myopathy (Danon disease). Nature 2000, 406:906-910

2. Danon MJ, Oh SJ, DiMauro S, Manaligod JR, Eastwood A, Naidu S, Schliselfeld LH: Lysosomal glycogen storage disease with normal acid maltase. Neurology 1981, 31:51-57

3. Nishino I: Autophagic vacuolar myopathies. Curr Neurol Neurosci Rep 2003, 3:64-69
4. Sugie K, Noguchi S, Kozuka Y, Arikawa-Hirasawa E, Tanaka M, Yan C, Saftig P, von Figura K, Hirano M, Ueno S, Nonaka I, Nishino I: Autophagic vacuoles with sarcolemmal features delineate Danon disease and related myopathies. J Neuropathol Exp Neurol 2005, 64:513-522

5. Furuta A, Wakabayashi K, Haratake J, Kikuchi H, Kabuta T, Mori F, Tokonami F, Katsumi Y, Tanioka F, Uchiyama Y, Nishino I, Wada K: Lysosomal storage and advanced senescence in the brain of LAMP-2deficient Danon disease. Acta Neuropathol 2013, 125:459-461

6. Eskelinen EL, Cuervo AM, Taylor MR, Nishino I, Blum JS, Dice JF, Sandoval IV, Lippincott-Schwartz J, August JT, Saftig P: Unifying nomenclature for the isoforms of the lysosomal membrane protein LAMP-2. Traffic 2005, 6:1058-1061

7. Fukuda M, Viitala J, Matteson J, Carlsson SR: Cloning of cDNAs encoding human lysosomal membrane glycoproteins, h-lamp-1 and h-lamp-2. Comparison of their deduced amino acid sequences. J Biol Chem 1988, 263:18920-18928

8. Cuervo AM, Dice JF: A receptor for the selective uptake and degradation of proteins by lysosomes. Science 1996, 273:501-503

9. Koga H, Cuervo AM: Chaperone-mediated autophagy dysfunction in the pathogenesis of neurodegeneration. Neurobiol Dis 2011, 43:29-37

10. Fujiwara Y, Furuta A, Kikuchi H, Aizawa S, Hatanaka Y, Konya C, Uchida K, Yoshimura A, Tamai Y, Wada K, Kabuta T: Discovery of a novel type of autophagy targeting RNA. Autophagy 2013, 9:403-409

11. Fujiwara Y, Kikuchi H, Aizawa S, Furuta A, Hatanaka Y, Konya C, Uchida K, Wada K, Kabuta T: Direct uptake and degradation of DNA by lysosomes. Autophagy 2013, 9:1167-1171

12. Tanaka Y, Guhde G, Suter A, Eskelinen EL, Hartmann D, LüllmannRauch R, Janssen PM, Blanz J, von Figura K, Saftig P: Accumulation of autophagic vacuoles and cardiomyopathy in LAMP-2-deficient mice. Nature 2000, 406:902-906

13. Manoni M, Tribioli C, Lazzari B, DeBellis G, Patrosso C, Pergolizzi R, Pellegrini M, Maestrini E, Rivella S, Vezzoni P, et al: The nucleotide sequence of a $\mathrm{CpG}$ island demonstrates the presence of the first exon of the gene encoding the human lysosomal membrane protein lamp2 and assigns the gene to Xq24. Genomics 1991, 9:551-554

14. Andrejewski N, Punnonen EL, Guhde G, Tanaka Y, LüllmannRauch R, Hartmann D, von Figura K, Saftig P: Normal lysosomal morphology and function in LAMP-1-deficient mice. J Biol Chem 1999, 274:12692-12701

15. Eskelinen EL, Schmidt CK, Neu S, Willenborg M, Fuertes G, Salvador N, Tanaka Y, Lüllmann-Rauch R, Hartmann D, Heeren J, von Figura K, Knecht E, Saftig P: Disturbed cholesterol traffic but normal proteolytic function in LAMP-1/LAMP-2 double-deficient fibroblasts. Mol Biol Cell 2004, 15:3132-3145

16. Bellettato CM, Scarpa M: Pathophysiology of neuropathic lysosomal storage disorders. J Inherit Metab Dis 2010, 33:347-362

17. Eskelinen EL, Illert AL, Tanaka Y, Schwarzmann G, Blanz J, von Figura K, Saftig P: Role of LAMP-2 lysosome biogenesis and autophagy. Mol Biol Cell 2002, 13:3355-3368

18. Schneede A, Schmidt CK, Hölttä-Vuori M, Heeren J, Willenborg M, Blanz J, Domanskyy M, Breiden B, Brodesser S, Landgrebe J, Sandhoff K, Ikonen E, Saftig P, Eskelinen EL: Role for LAMP-2 in endosomal cholesterol transport. J Cell Mol Med 2011, 15:280-295

19. Virtanen I, Ekblom P, Laurila P, Nordling S, Raivio KO, Aula P: Characterization of storage material in cultured fibroblasts by specific lectin binding in lysosomal storage diseases. Pediatr Res 1980, 14: $1199-1203$

20. Roy E, Bruyère J, Flamant P, Bigou S, Ausseil J, Vitry S, Heard JM: GM130 gain-of-function induces cell pathology in a model of lysosomal storage disease. Hum Mol Genet 2012, 21:1481-1495

21. Huynh KK, Eskelinen EL, Scott CC, Malevanets A, Saftig P, Grinstein S: LAMP proteins are required for fusion of lysosomes with phagosomes. EMBO J 2007, 26:313-324

22. Crotzer VL, Glosson N, Zhou D, Nishino I, Blum JS: LAMP-2deficient human B cells exhibit altered MHC class II presentation of exogenous antigens. Immunology 2010, 131:318-330 
23. Furuta K, Ikeda M, Nakayama Y, Nakamura K, Tanaka M, Hamasaki N, Himeno M, Hamilton SR, August JT: Expression of lysosome-associated membrane proteins in human colorectal neoplasms and inflammatory diseases. Am J Pathol 2001, 159:449-455

24. Fortunato F, Bürgers H, Bergmann F, Rieger P, Büchler MW, Kroemer G, Werner J: Impaired autolysosome formation correlates with Lamp-2 depletion: role of apoptosis, autophagy, and necrosis in pancreatitis. Gastroenterology 2009, 137:350-360, 360.e1-5

25. Peschel A, Basu N, Benharkou A, Brandes R, Brown M, Dieckmann R, Rees AJ, Kain R: Autoantibodies to hLAMP-2 in ANCA-negative pauci-immune focal necrotizing GN. J Am Soc Nephrol 2014, 25: 455-463

26. Komatsu M, Waguri S, Chiba T, Murata S, Iwata J, Tanida I, Ueno T, Koike M, Uchiyama Y, Kominami E, Tanaka K: Loss of autophagy in the central nervous system causes neurodegeneration in mice. Nature 2006, 441:880-884

27. Hara T, Nakamura K, Matsui M, Yamamoto A, Nakahara Y, SuzukiMigishima R, Yokoyama M, Mishima K, Saito I, Okano H, Mizushima N: Suppression of basal autophagy in neural cells causes neurodegenerative disease in mice. Nature 2006, 441:885-889

28. Di Malta C, Fryer JD, Settembre C, Ballabio A: Astrocyte dysfunction triggers neurodegeneration in a lysosomal storage disorder. Proc Natl Acad Sci U S A 2012, 109:E2334-E2342
29. Dehay B, Martinez-Vicente M, Caldwell GA, Caldwell KA, Yue Z, Cookson MR, Klein C, Vila M, Bezard E: Lysosomal impairment in Parkinson's disease. Mov Disord 2013, 28:725-732

30. Subramaniam SR, Chesselet MF: Mitochondrial dysfunction and oxidative stress in Parkinson's disease. Prog Neurobiol 2013, 106-107: $17-32$

31. Cuervo AM, Stefanis L, Fredenburg R, Lansbury PT, Sulzer D: Impaired degradation of mutant alpha-synuclein by chaperonemediated autophagy. Science 2004, 305:1292-1295

32. Kiffin R, Christian C, Knecht E, Cuervo AM: Activation of chaperonemediated autophagy during oxidative stress. Mol Biol Cell 2004, 15: $4829-4840$

33. Vogiatzi T, Xilouri M, Vekrellis K, Stefanis L: Wild type alphasynuclein is degraded by chaperone-mediated autophagy and macroautophagy in neuronal cells. J Biol Chem 2008, 283: 23542-23556

34. Xilouri M, Brekk OR, Stefanis L: Alpha-synuclein and protein degradation systems: a reciprocal relationship. Mol Neurobiol 2013, 47:537-551

35. Tsuchiya Y, Okuno Y, Hishinuma K, Ezaki A, Okada G, Yamaguchi M, Chikuma T, Hojo H: 4-Hydroxy-2-nonenal-modified glyceraldehyde-3phosphate dehydrogenase is degraded by cathepsin G. Free Radic Biol Med 2007, 43:1604-1615 